\title{
Global Perspectives: The University of South Aus- tralia (UniSA) Case Study
}

Reviewers

\begin{abstract}
This case study describes current developments in the change processes that are underway at the University of South Australia (UniSA) as it develops from a dual mode institution to one that embraces flexibility in delivery of all of its courses and programs. Forces operating in the context of higher education are causing traditional institutions to become dual mode. Institutions that were already operating as dual mode are developing a proliferation of program delivery arrangements that move beyond hybridisation. A number of Australian institutions claim to provide flexibly delivered courses where student centred learning processes are facilitated through the use of information and communication technologies.

Hybridisation and the move to flexible delivery in Australia has partly been driven by changes in the socio-economic context of higher education that have forced universities to compete for income to sustain their operating costs. Offshore teaching and the provision of onshore fee paying courses for international students have required changes to delivery processes for resource-based teaching and online technologies and these changes have washed through institutions. However, for some institutions the development of flexible delivery has been to achieve a wider range of educational purposes for all students. Such purposes are often described in terms of the shift in focus: for example, from teaching to learning; from elite to inclusive; from "producer" to "consumer;" from local perspective to international; from credentialing (four year degree) to life-long learning (40 year degree).

This case study looks at the ways in which UniSA course, student, regulatory, logistical and technological systems or subsystems are changing, both in response to extra-institutional influences and in relation to institutionwide development of greater flexibility in teaching, learning and program delivery. This analysis highlights the ways in which these subsystems interact with each other and the critical importance of shared vision to coordinate changes on multiple fronts within the institution and to facilitate internalisation and ownership of such change by its staff.

The case study highlights how the logistical assumptions and arrangements of online education are significantly different in kind from those of traditional face-to-face or distance education and argues that moves to
\end{abstract}


Global Perspectives: The University of South Australia (UniSA) Case Study 2

online education therefore require pervasive change. At the same time, online education can provide an integrating framework for different forms of delivery, thereby achieving synergies and economies of scale.

\section{Introduction}

This case study explores in detail the experience of the University of South Australia (UniSA) in attempting to position itself to its advantage in a period of rapid and far-reaching change. The developments described in this paper go beyond hybridisation between distance and face-to-face forms of delivery, to the evolution of new forms enabled by information and communications technologies. Nevertheless, hybridisation has been a starting point for developments. The infusion of the technology and techniques of distance education into traditional modes of teaching and learning has meant that UniSA has had to plan for future learning environments that both encompass hybridisation and develop flexibility in the provision of programs.

UniSA was formed in 1991 and has sought to redevelop and reshape the traditional forms of on campus and distance education inherited from its antecedent institutions. This reshaping is creating flexible modes of delivery to serve an increasingly diverse domestic student clientele and an increasingly international clientele studying on and offshore. These developments have challenged all of the constituent parts of the institution to rethink and reinvent themselves in quite fundamental ways. As a "work in progress" study, UniSA provides lessons and examples that may serve to inform other institutions embarking on similar journeys (Busuttil et al., 1999).

To understand the changes occurring at the institutional level, it is important to appreciate the various contexts in which the University operates and from which the drivers for change derive. The national and local contexts are the starting point.

\section{The Context of Higher Education in Australia}

A range of environmental factors ${ }^{1}$ has challenged the Australian higher education sector over the last decade. Globalisation of the economy, changing patterns of work and employment and the emergence of the knowledge economy have changed demands for education from elite to mass, while at the same time giving rise to increased labour market inequalities and thus, access to goods and services by certain sectors of society. ${ }^{2}$ Changing demographics arising from changes in birth rates and patterns and levels of migration mean that Australia, like other Western nations, is experiencing the effects of ageing populations and

International Review of Research in Open and Distance Learning 
changes in the dependency ratios (ratio of workers to non-workers). Communication and information technologies have become pervasive, changing the nature of work and enabling communication and business to occur regardless of time of day or country in the world. Government funding of higher education has been reduced substantially, meaning that institutions have had to develop new sources of income and become more transparent and responsive to their new or changing clienteles. Business and education are increasingly borderless, demanding new levels of cultural literacy as participants communicate and engage across cultures and languages. The changes are summarised, albeit in simplified form, in Table 1 below.

The effects of such shifts on staff and structures in universities have been profound, and challenge institutions to react and/or anticipate and adapt. ${ }^{3}$ Universities must now compete against one another and against emerging educational providers for government funded and fee-paying students. Therefore, they must develop business capabilities across a broad spectrum of staff to initiate and sustain income generation ventures, develop skills, contacts and capabilities to operate in international markets in a range of countries (but predominantly in emerging economies in Asia). In short, universities must become learner centred as an essential competitive characteristic, and they must use information and communication technologies intelligently.

University responses to these drivers necessarily influence all aspects of their operations:

- Shaping of roles and expectations about being a student in a student centred institution

- The roles, skill sets and bases of employment of staff, both academic and administrative

- Structures and governance

- Administrative and management information systems and processes

- Courseware and delivery mechanisms

Policy changes in these areas are considered later in the section on the regulatory subsystem. 
Global Perspectives: The University of South Australia (UniSA) Case Study 4

\section{The Context of Higher Education in South Aus- tralia}

The state of South Australia has a particular suite of circumstances that may act to amplify or mitigate these more global forces. Some features of South Australia that impact on higher education in the state are:

- An ageing population in relation to other states, with lower fertility, net emigration to other states and low levels of international migration - i.e., low growth in the domestic student market

- Slower economy and narrower industry base, higher levels of unemployment, lower labour force participation rates, and lower average incomes i.e., reduced local employment opportunities for graduates.

This is balanced to some extent by a lower cost of living, ease of mobility, the emergence of a number of boutique industries, and major investment in a small number of large infrastructure projects.

\section{The University of South Australia: The Institu- tional Context}

UniSA was established as the newest university in the state of South Australia in 1991. It represented a merger of the then South Australian Institute of Technology and parts of the SA College of Advanced Education, each of which was also the product of a number of antecedent institutions, including some that date back to the South Australia's colonial history. In defining itself as a university, UniSA has, in the ten years since foundation, developed a managed approach to establishing a vision, policies, and priorities that steers its teaching, research and community service. In some ways, the timing of its formation meant that it was more free to shape itself in response to the emerging drivers than has perhaps been the case with more established institutions.

The University's enabling legislation requires it to provide education for the broadest range of Australians and address the educational needs of indigenous people.

The University in 2001:

International Review of Research in Open and Distance Learning 
Global Perspectives: The University of South Australia (UniSA) Case Study 5

- Operates six campuses - five in metropolitan Adelaide and one in a regional centre of South Australia

- Has approximately 27,000 students, making it the largest in the state

- 5,763 International students - 1,566 study on campus and a further 4,197 are enrolled offshore

- 2,000 staff

- An annual budget of more than \$AUS200 million

The institution has been actively engaged in developing its learning environment to take advantage of new technologies and has determined its directions towards $2005 .{ }^{4}$ UniSA has an overarching teaching and learning framework built around concepts of student centred learning, development of a set of graduate qualities as outcomes and enabling these through flexible delivery. ${ }^{5}$ Flexible delivery encompasses processes, products and mechanisms that enable the UniSA to deliver its programs and courses on campus, at a distance, online and offshore. In positioning the University to exploit opportunities for income generation in a range of educational territories, flexibility is one aspect of an institutional capability that is regarded as critical as curriculum. ${ }^{6}$

Flexible delivery processes include: conventional text based distance education; twinning arrangements with other higher education institutions; the provision of services by external bodies in a vertically disaggregated form of delivery; global partnerships with other universities to deliver offshore programs; face-to-face teaching in offshore locations; involvement in delivery of distance education in a national open learning body; online delivery; and various combinations and permutations of these approaches. As previously mentioned, the capacity to develop such a range of delivery options arises from the starting points of hybridisation in which the capacities of a dual mode operation have been extended and enhanced in various ways. 


\section{Critical Incidents in Developing Flexible Delivery Capability}

\section{Course subsystem}

In 1993, UniSA articulated a vision of its future learning environment to the year 2003. Among other features this environment would be characterised by flexible teaching and learning strategies that emphasises student management of learning and communication technologies.

A key decision of the University was taken in 1995 to expand its range of services and support involved with facilitating conventional distance mode studies to all forms of program delivery. This has been described in detail in a previous paper in this journal. ${ }^{7}$

In May 1999, UniSA's Academic Board adopted new processes for the development, amendment and approval of university programs. Traditionally, program approval processes focused on the content of the courses that made up a program and involved judgments about the intellectual coherence, relevance, and standards associated with discipline based content. The new processes added to these concerns issues about resources, delivery mechanisms and costs, mechanisms to support student learning, and whether the program was provided as flexibly as possible.

The effect of these changes has been to add the logistics of delivery to curriculum issues so that a more accurate picture of programs can be gained. Issues such as start-up costs; resource requirements (including the impact of the program on library and information technology resources); the appropriateness of delivery mechanisms for student cohorts involved in the program; and student administrative arrangements are now considered formally within an approvals process. Formal consideration of such issues is critical to developing and maintaining a capacity to deliver programs flexibly. These decisions have been paralleled by important changes in other subsystems in the teaching and learning environment of the institution.

\section{Student Sub-System}

A further critical incident in developing flexible delivery capability has been changes to the student sub-system. This sub-system comprises:

- Administrative systems (i.e., systems that handle enrolments, etc.) 
Global Perspectives: The University of South Australia (UniSA) Case Study 7

- Administrative services (i.e., services that support enrolment, fee payment, graduation etc.)

- Learning services (i.e., library, information technology, language and learning support, counselling and welfare services)

Together with discipline based teaching and learning activities the smooth operation of these systems and the availability and variety of services contribute to student learning and satisfaction. However, prior to re-engineering the student system, its components were structurally and physically separate and experienced by students as fragmented entities disconnected from the course subsystem. Administrative systems had been heavily mediated by staff and available only during traditional business hours, with congestion at peak periods such as enrolment. Administrative staff spent time on data entry and verification at the expense of contact with students and staff. Administrative systems had been designed around meeting government information requirements for funding, rather than as sources of information for students and staff. Learning services were heavily mediated by staff and students experienced difficulty in getting to see advisers. Services were often disconnected from mainstream teaching and learning processes in that they were seen as "remedying deficits" in students.

A major critical incident was a project to develop a new student administration system (initiated in 1999 and implemented in late 2001) and to re-engineer administrative services and learning services. In short, each component of the student system was changed, with attention given to the complementary operation of services. The main objectives to be met in a changed administration system were:

- To be student centred (i.e., permit and encourage student access to and control over their teaching and learning environment, including administrative aspects) and service oriented, integrating administrative services with the teaching and learning environment.

- To provide the flexibility to manage a range of traditional and non-traditional educational business on and offshore, face-to-face or distributed and in the new worldwide e-business hours of $24 \times 7$ rapidly supplanting the traditional (9 to 5$) \times 5$. 
Global Perspectives: The University of South Australia (UniSA) Case Study 8

- To support devolved management decision-making, institutional responsiveness and quality assurance processes by making comprehensive information reporting widely available.

Likewise, in re-engineering administrative services (Campus Central) and complementary learning services (Learning Connection) the objectives were:

- To be highly visible, accessible and coordinated, integrating a range of high quality, consistent and coordinated services and resources across multiple campuses accessible in a variety of ways - by phone, fax, email, face-toface and online.

- To recognise student diversity and study modes (on campus and at a distance) and offering multiple pathways and options to allow students to choose those that best suit them.

- To position students as active and capable agents, recognising the developmental nature of educational programs and that student needs and circumstances vary over student lifecycle stages.

The development of Learning Connection and Campus Central reflects the recognition that recent changes in higher education require new approaches and not simply incremental adjustments to structures and strategies designed for previous conditions. Face-to-face services are supplemented and extended by the imaginative application of technology. Actual services are mirrored by virtual services that provide student access from anywhere at any time. Virtual services are largely unmediated - students are free to select the services they need, when they need them.

A new service provided through Learning Connection illustrates how re-engineering is directed at valuing flexible approaches to teaching and learning. If they are provided with the means to chart their development of skills and abilities and thus choose to develop or extend skills in particular ways, students are better able to exercise choice and control over the opportunities provided to them through flexible teaching and learning. UniSA has developed student operated online software that provides the means to review what they are learning, as well as information about how their studies develop particular qualities and outcomes. Students are encouraged to record how their activities and assessment contribute to the development of such qualities throughout their studies. ${ }^{8}$ It is through this mechanism that students recognise and exercise control over their learning. ${ }^{9}$

International Review of Research in Open and Distance Learning 
Global Perspectives: The University of South Australia (UniSA) Case Study 9

Changing the student sub-system has been a critical and vital component of shaping a teaching and learning environment that supports and fosters flexible delivery. In developing capabilities in this area, attention has been given to how students experience the total institutional environment and this has meant that there are consequent changes to services that are shaped by both new systems and overarching educational values such as promoting flexibility, choice and student centred-ness.

Re-engineering systems and using technology to achieve student centred learning present fundamental and difficult challenges as they require a changed view of the power relationship (often implicit and covertly applied through transmission models) between students and staff.

\section{Regulatory Subsystem}

The environmental changes detailed in the earlier part of this case study have demanded significant policy development, not simply incremental adjustments to existing policies. The key policy responses to these changes are in the areas of:

- Commercialisation, intellectual property and staff rewards for commercial activity

- Copyright

- Regulation of contractual relationships when operating with external parties, especially for offshore delivery of education

- Quality assurance and improvement of programs, courses and teaching

- Addressing quality issues arising from casualisation of teaching especially in relation to adequate induction of staff

- Issues of entry conditions into programs in relation to English language competency 
Global Perspectives: The University of South Australia (UniSA) Case Study10

- Provision of technology infrastructure and interfaces to support off campus teaching and learning

- Quality assurance of online delivery The key policy statements and their timing are shown in:

\section{Logistical Subsystem}

The procurement and supply of resources to support flexible delivery of the UniSA's programs and courses was informed by two historical circumstances. First, with a strong history of dual mode delivery, staff members were accustomed to teaching students both on-campus and at a distance, assuming equivalence of academic standards and expectations, but employing different delivery methods. This environment was one where the adaptation of distance education methodologies to online and resource-based delivery was seen as further increasing the flexibility of delivery, rather than a step without historical precedent. The second circumstance was the UniSA's success in distance provision, through a central unit managing the required administrative and production services to support distance teaching and learning.

This capacity as a dual mode (i.e., face-to-face and distance) institution proved, however, a double-edged sword. On the one hand, it provided the University with experience, technologies and educational understandings necessary to introduce technologies into its delivery processes for all of its programs and students. On the other hand, the production house methodologies used to employ these technologies and create teaching materials were not sufficiently scalable to the extent required for UniSA's strategic directions.

Models that had been successful in the past proved unsustainable because the production requirements of traditional distance delivery created bottlenecks when the number of products to be produced in a timeframe outstripped resources and scheduling capacity. This has been a perennial problem in the production of traditional, largely print-based distance learning materials. The power of Web-based tools that can be made available on the desktop has rendered this production line approach inefficient. This meant moving from a production model to an enabling (professional development) model. This change is illustrated in:

A professional development model enables academics to produce, maintain and revise their own teaching and learning resources without the intervention of specialist instructional design or production staff. It depends upon "up-skilling" through just-in-time professional development - it provides tools and information relevant to particular needs of teachers in developing learner centred 
Global Perspectives: The University of South Australia (UniSA) Case Study11

approaches and materials. It uses structured means for up-skilling through wizards, templates and decision algorithms. The application of such tools to teaching and learning situations involve decisions that take into account key educational and contextual issues.

When professional development models employ communication and information technologies to deliver up-skilling they become more scalable with the potential for universal uptake by all teaching staff, more relevant because the information and skill development takes place just-in-time, and more effective as personal teaching methodologies become embedded in the learning materials developed. When such models are combined with quality assurance mechanisms that evaluate the application of skills to teaching and learning developments (i.e., peer review) they provide a powerful approach to improving teaching, learning, and resources for teaching and learning.

The move to a professional development model from a production model is not a simple matter. A major debate within distance education has been about the balance between professional development of distance teachers and the provision of specialist educational and production assistance. What makes this situation different at this time is the development of "smart tools" and the provision of just-in-time information via communications and information technologies - it is the desktop capacities of the technology coupled with desk top delivery of skill formation and development that takes the enabling capacity to new levels and tips the balance to scalable professional development.

This move to an enabling (professional development) model has been supported by a number of parallel and coordinated shifts. First of these was the establishment of a dedicated project team to develop an online delivery platform UniSAnet - that was interoperable with UniSA's IT environment, was scalable to every course offering, and had embedded within it the necessary "smart tools." (This development is described in more detail in the next section on the technological subsystem.) Second, staff development services were reshaped to provide extra support for teaching staff in the area of using online methods in teaching and learning. Third, UniSA upgraded its IT infrastructure and computer pools.

Application of a professional development model and parallel shifts provided the impetus for the development of online teaching and learning. This development has blurred the boundaries between on-campus and distance teaching and learning approaches and has given rise to hybrid arrangements, which challenge the assumptions behind on campus (face-to-face) and traditional distance education. A convenient characterisation of hybrid situations is "online education" as it may be resource-based learning used by on-campus students (and combined with face-to-face teaching) or, equally, used by off campus students (with or without face-to-face components) studying the same course. Where the information and communication capacities of online technologies are fully exploited, it is possible to characterise this as a new mode with distinctive assumptions and differences from on and off campus teaching.

International Review of Research in Open and Distance Learning 
Global Perspectives: The University of South Australia (UniSA) Case Study12

It is possible to identify particular logistics associated with characterisations of face-to-face, distance and online education - that is, the characterisations contain assumptions about the effective "operation" of labour and materials to achieve their goals. In face-to-face contexts, the focus is on the teacher's performance in lectures and tutorials. Effort is expended on time tabling - i.e., the coordination of staff, students, space and time. A new group of students requires a new performance, and this requirement for "repeat performances" increases the marginal costs of delivery. In this teacher centred mode, materials support the performance of the teacher.

With distance education the prime focus is on teaching and learning materials. Materials support student learning. Teacher and ancillary labour is expended on the development, production, duplication and dispatch of these materials. However, once this process is in train, materials can be provided to many students and at reasonably low marginal cost, as they are produced on the assumption of having a particular "shelf-life" beyond the immediate delivery period. In this resource-centred mode, materials support the activity of the learner.

In an online teaching context the teacher and the student gain access to materials created by the teacher, other students, or other parties using the evolving World Wide Web. Access is generally provided asynchronously, independent of place, allowing the accumulation of a collective and collected wisdom within and between learning experiences. The educational experiences can be ephemeral (e.g., in synchronous chat or broadcast techniques) or lasting (e.g., in asynchronous discussions or Web-based resources). Any party can create materials in the educational interchange, allowing just-in-time and learner-centred virtual environments. Costs of online delivery can vary depending on the degree of human interaction (labour) required, the amount of custom-built resources and the sophistication of technologies employed.

Clearly, the above applications of labour and materials are representations that serve to highlight the different logistics associated with the modes. They serve a useful conceptual purpose of clarifying particular positions about "logistics." However, in practice, the logistical arrangements of delivery of teaching and learning, is usually a complex mix of the assumptions and processes characterised by these modes. The logistical assumptions and arrangements of these three modes are summarised in Table 3.

The logistical assumptions and arrangements of these three modes are summarized below:

Moves from face-to-face or traditional distance education to online education represent significant changes in the assumptions on which teachers, learners and support staff go about their business and to the technological infrastructure and skill base that support the moves. Achieving a migration from the "post-box and hard text" delivery of conventional distance education to online requires at least three preconditions. First, the technical infrastructure needs to be 
Global Perspectives: The University of South Australia (UniSA) Case Study13

transparent to users. Second, its operational framework must address teaching and learning decisions when it describes its functions. Third, systematic and local professional development in online teaching and learning using a "just-intime" and "just-for-me" approach must be available to academics.

\section{Technological Subsystem}

As previously noted, UniSA developed a vision of its future learning environment in 1993. In 1997, it changed its budget profile ${ }^{11}$ to enable it to build the necessary technological infrastructure to support online delivery.

Key to the success in using information technologies is the degree to which the technological approaches chosen were viable within the infrastructure of the institution. To move beyond small-scale and localised innovation, an institutionwide technology strategy to support large-scale initiatives was necessary. A comprehensive information management strategy was seen as the most efficient and effective approach and was made possible by a planned approach to IT across the University. This management strategy would require support and coordination by a governance structure that included the key service units of the University and employed consultative mechanisms involving members of senior management in UniSA-wide policy committees.

This management approach mandated a number of technical decisions to enable a large-scale technological environment. These included the establishment of a common email system (MS Exchange), a common authentication system (MS NT and Exchange accounts) and common corporate database systems (Oracle RDMS). By ensuring that data were stored once and re-used, efficiencies were gained and a universal infrastructure was built. Onto this common infrastructure was built a common online delivery system (UniSAnet), which was integrated into it, thus saving effort and producing scalable tools that operated in ways that were consistent with existing software. Students gained access to this platform via their own Internet provider, or via standardised student computer pools (Windows PCs with common software installations, e.g., MS Office).

The development of UniSAnet in this environment involved the following steps: ¡UL TYPE $=1$ i

Convert textual information from the University Calendar to database format to produce a course database. This then allowed the print calendar to be produced from the database on demand.

Integrate corporate databases (e.g., human resources, student records) with the

International Review of Research in Open and Distance Learning 
Global Perspectives: The University of South Australia (UniSA) Case Study14

course database.

Develop technologies to convert existing print, electronic and web resources into forms linked to and from the course database.

Develop Web-based authoring tools (e.g., wizards, forms etc.,) to allow staff to create static and interactive Web-based learning resources (e.g., HTML pages, discussion groups, quizzes, chat groups, etc.)

Provide Web-based systems that allow users to suggest changes to corporate information (e.g., course information, personal details).

Integrate new features as developed (e.g., administrative features, assignment submission, evaluation mechanisms, support mechanisms).

Secure all of the above with a consistent authentication mechanism, so students and staff need only one username and password for all resources and processes.

Link external services as appropriate (e.g., commercial book suppliers).

The UniSAnet provided a scalable and interoperable information management system that also afforded consistent interfaces for student learning. The process of developing a knowledge management strategy is further described by Reid. ${ }^{12}$ In reflecting on the development of UniSAnet, it is clear that a number of fundamental changes were introduced. The use of standardised templates for both print and online resources allowed the convergence of print and online resources into interchangeable forms. Whereas in the past, online developments tended to be based on isolated individual initiatives, the mandated approach allowed staff development and technical support to be available to all staff wishing to teach online. By keeping the skill requirement low and devolving control over resource development and online interactions to individual academics, it was possible to move to the enabling model described above.

International Review of Research in Open and Distance Learning 
Global Perspectives: The University of South Australia (UniSA) Case Study15

\section{Intended and Unintended Consequences}

UniSA's statement of strategic intent spells out the intended consequences of its adjustment to the impact of the environmental forces detailed at the beginning of this case study. UniSA's capabilities in mixed mode delivery have served as a platform for accelerated development in the variety and use of flexible program arrangements. This change was anticipated some years earlier when the University reconstructed its Distance Education Centre as the Flexible Learning Centre and opened up to all programs, services previously available only to external programs.

UniSA's intended to move its teaching and learning towards a learner centred approach and saw flexible approaches to delivering its courses, including online approaches, as a way to increase learner control over their learning, access and choice. Delivery mechanisms have served as a means to the end of learner centred-ness. At the same time, a powerful and practical driver for changing to online delivery approaches has been the need to market courses and teaching for profit. A practical consequence is that a delivery mechanism has become a means to efficient production, distribution, and teaching in ways that create a competitive market for educational commodities. Competitive pricing can result from adopting transmission approaches to teaching. Thus, competing in the market made possible by online approaches can produce products that work against educational goals of learner centred-ness, where courses developed for a competitive market are used within the institution.

Goals of learner centred-ness can be eroded. This is especially the case where pricing arrangements have been adjusted to suit the economic circumstances of clients and the materials and teaching approaches have been pared down to suit a costing framework. Transmission models provide few opportunities for students to develop a range of highly valued graduate skills such as critical thinking and problem solving, communication, working in groups and individually, operating as socially responsible professionals and bringing international perspectives to bear on their work. The challenge to institutions here is to be aware of such possible consequences and take steps to ensure that the capacities of online education are exploited in ways that preserve learner centred-ness.

\section{Implications of Lessons Learnt with Regard to Distance Education, Open Learning and Flexible Delivery}

In general, academic staff members regard increasing flexibility of program delivery as synonymous with the translation of teaching methodologies to an online environment. This translation involves using techniques of open and distance 
learning within an electronic environment. Although, the teaching embedded within conventional distance teaching materials is seen as the key means of teaching, the communication capacities of the online environment are underutilised. Nevertheless, the move to online is important because it forms the starting point for further developments that subsequently exploit the capacities of information and communications technologies.

A related lesson is that online materials and communications developments are likely to provide a common thread and organising factor for flexible delivery. It is our experience that where a course has a variety of student cohorts (i.e., onshore face-to-face, distance education, offshore involving a twinning partner) it is the online component that often provides information about the course and its objectives, assessment, access to key resources for learning, means by which advice on study skills and other facilitative advice is provided, mechanisms for student feedback on the effectiveness of the course, processes for submission of student assignments and so on. In this way online processes begin to shape major components of the learning experience. Because online components play this role, it is essential that the preconditions mentioned earlier are in place; without such conditions, the capability to integrate modes of delivery and achieve synergies and economies are lost.

The online environment provides academic staff with experiences that demonstrate how students exercise agency and responsibility over their learning. That is, many academics meet the notion of flexible learning through their interactions with online learners. When students choose to use the information and communications capabilities of the online environment in particular ways, they radically alter the traditional power relations between teacher and learner. For example, students can create new boundaries for the curriculum through researching and using Web-based resources that make them more knowledgeable than teachers in that area; learners can use the communications capacities to challenge the ways that they are treated as learners; students may challenge the need for face-to-face experience in conventional transmission mode classes simply because they prefer more enriching experiences delivered through the Web-based resources, and so on. That learners become partners, not dependents, is a key test for flexible learning.

Another lesson learned is that when an institution moves beyond hybridisation it can only do so if it is able to manage and coordinate simultaneous changes on a number of fronts. The teaching and learning environment of an institution responds like an ecological system - change in one area generates adaptive, and in some cases radical changes in other areas. The pace and extent of change can lead to change fatigue where individuals start to lose interest in or recast institutional visions into their own version of what is realistic. Difficulties in communicating the effects of multiple change, and limitation in the capacity of individuals to internalise the effects of change, can mean that they stop engaging in the learning processes that underlie successful change.

International Review of Research in Open and Distance Learning 
Global Perspectives: The University of South Australia (UniSA) Case Study17

UniSA recognises that change at the pace and scale required in the current context involves all of its staff, as well as the organisation itself, to be engaged in learning processes (including learning through mistakes). To this end, UniSA has appointed a coordinator of organisational learning to assist in activities that analyse change processes, and integrate and communicate changes that are taking place within the University.

Moving beyond hybridisation can mean involvement in the "vertical disaggregation" of program delivery. Different functions may be taken up depending upon the nature of a particular business partnership and type of vertical disaggregation. For example, as a partner in Open Learning Australia, UniSA has enjoyed a strong producer role in course design, materials production and teaching, whereas in other partnerships, UniSA might take a stronger role in the areas of quality assurance, standards modification and accreditation, while partner institutions undertake the teaching roles. The capacity to be involved in activities globally is a function of the institutional capacities to deliver programs flexibly.

A final lesson is that moving beyond hybridisation will mean rebalancing the "clicks" and "bricks" components of an institution. The move to clicks may mean that physical amenities such as cafeterias, sporting facilities, and student association facilities become less used and valued. A clicks culture, however, can extend more readily to bring together alumni (or professional groups) thereby developing virtual communities with a continuing connection with the University. Developing a clicks institution has required that UniSA restructure its budget profile to bring about increases in funding for its library and information technology services and, as a corollary, to consolidate its brick structure by rationalising its campuses and upgrading its physical facilities.

\section{Conclusions}

The moves by UniSA beyond hybridisation to flexible delivery have been the result of a sustained process of change over the relatively short life of the institution. The moves have required the creation of a vision about its future teaching and learning environment, outcomes it seeks for its graduates, its relations with its students, and attention to how these visions are shared among stakeholders. It has required a determined and significant restructuring of its budget, construction of infrastructure to support online delivery across the institution, and invention and reinvention of aspects of its structure and functions. In common with many Australian institutions, UniSA has undergone and continues to undergo change of an unprecedented pace and scale, well beyond hybridisation of its traditional duality of teaching modes.

International Review of Research in Open and Distance Learning 
Global Perspectives: The University of South Australia (UniSA) Case Study18

\section{References}

Busuttil A. (1999). Report on the project Exploring Flexible Teaching and Learning Across the University of Western Sydney (Vol. 1 \& 2). Macarthur, University of Western Sydney: Centre for Enhancement of Learning and Teaching

Gallagher, M. (2000). The emergence of entrepreneurial public universities in Australia.Paper presented at the IMHE General Conference of the OECD, Paris, France. DETYA Higher Education Division Occasional paper series 00/E,[Online] Available at: http://www.deetya.gov.au/highered/occpaper/00e/00e.pdf

Gallagher, M. (24 July 2001). Lifelong learning: demand and supply issues - some questions for research. Paper presented at The Business/Higher Education Roundtable Conference on The Critical Importance of Lifelong Learning.

King, B. (1999). Distance Education in Australia. In Harry K. (Ed.) Higher Education through Open and Distance Learning. World review of distance education and open learning (264-276). Vol. 1. Routledge \& The Commonwealth of Learning.

King, B., McCausland, H. \& Nunan, T. (2000). Converting to online course and program delivery, global perspectives: the University of South Australia case study, The International Review of Research in Open and Distance Learning, 1, 2 (p. 25).

Nunan Ted (2000). Exploring the Concept of Flexibility (2000) In Jakupec V. and Garrick J. (Eds.) Flexible learning, human resource and organisational development (47-66). London and New York: Routledge.

Nunan, T., George, R., and McCausland, H. (2000). Implementing graduate skills at an Australian university. In Fallows, S. and Steven, C. (Eds.) Integrating key skills in higher education (57-66). London: Kogan Page.

Reid, J. (1997, July). Summary of Discussions. Paper prepared for the Higher Education Council and the National Academies Forum: Joint Seminar on the Undergraduate Curriculum. Canberra, New South Wales.

Reid, I. C. (2001). Knowledge: How Should Universities Manage IT? Perspectives, 5 (1), 21-27.

University of South Australia (1997, February). Corporate planning: Changing our budget profile [roneo].

Woodhouse D (2001). Australian Universities Quality Agency: Audit Manual, Draft Edition version 0, p. 9.

International Review of Research in Open and Distance Learning 
Global Perspectives: The University of South Australia (UniSA) Case Study19

\section{Endnotes}

1. For example, Considine, M., Marginson, S. \& Sheehan, P. with assistance of Kumnick, M. (April 2001). The comparative performance of Australia as knowledge nation. Report to the Chifley Research Centre [Online] Available at: ftp://ftp.alp.org.au/pub/federal/reports/chifley_kn.pdf. Reid, J. (1997, July). Summary of Discussions. Paper prepared for the Higher Education Council and the National Academies Forum: Joint Seminar on the Undergraduate Curriculum. Canberra, New South Wales. Gallagher, M. (2000) The emergence of entrepreneurial public universities in Australia: paper presented at the IMHE General Conference of the OECD Paris. DETYA Higher Education Division Occasional paper series 00/E [Online] Available at: http://www.deetya.gov.au/highered/occpaper/00e/00e.pdf

2. Gallagher, M. (24 July 2001). Lifelong learning: Demand and Supply Issues some questions for research. Paper presented at The Business/Higher Education Roundtable Conference on The Critical Importance of Lifelong Learning. [Online] Available at: http://www.detya.gov.au/highered/otherpub/lifelong/default.htm

3. For a review of structural change in Australian provision of distance and flexible education, see King, B. (1999). Distance Education in Australia. In Harry, K. (Ed.) Higher Education through Open and Distance Learning. World Review of Distance Education and Open Learning. Vol. 1. (264-276). Routledge \& The Commonwealth of Learning.

4. UniSA 2005 [Online] Available at: http://www.unisa.edu.au/pln/Plans.htm

5. UniSA Teaching and Learning framework [Online] Available at: http://www.unisanet.unisa.edu.au/learningc

6. Nunan Ted, (2000). Exploring the Concept of Flexibility. In Jakupec V. and Garrick J (Eds.) Flexible Learning, Human Resource and Organisational Development (47-66). London and New York: Routledge.

7. King, B., McCausland, H. \& Nunan, T. (2000). 'Converting to online course and program delivery, global perspectives: the University of South Australia case study', The International Review of Research in Open and Distance Learning, 1,2 (p. 25).

8. Nunan, T.; George, R., \& McCausland, H. (2000). Implementing graduate skills at an Australian university. In Fallows, S. and Steven, C. (Eds.) Integrating key skills in higher education. (57-66) London: Kogan Page.

9. UniSA recording of achievement [Online] Available at: http://www.unisanet.unisa.edu.au/gradquals/shappe

10. University of South Australia (1997, February). Corporate planning-Changing our budget profile [roneo].

11. Reid, I. C. (2001). Knowledge: how should universities manage IT? Per- 
Global Perspectives: The University of South Australia (UniSA) Case Study20

spectives, 5(1), 21-27.

12. UniSA Statement of strategic intent [Online] Available at: http://www.unisa.edu.au/pln/Reports/Intent.ht

\section{Citation Format}

Nunan, Ted, Reid, Ian \& McCausland, Holly (January, 2002) Global Perspectives: The

University of South Australia (UniSA) Case Study. International Review of Research in Open and Distance Learning: 2, 2. http://www.icaap.org/iuicode?149.2.2.2 
Table 1

\begin{tabular}{|c|c|}
\hline From: Teacher Centred & To: Learner Centred \\
\hline Higher education for the elite & Higher education for the \\
\hline Homogeneous student body & Diverse student body \\
\hline $\begin{array}{l}\text { Few international students - education as } \\
\text { 'foreign aid' }\end{array}$ & $\begin{array}{l}\text { Many international stude } \\
\text { education as internationa }\end{array}$ \\
\hline $\begin{array}{l}\text { Small, domestic distance education operation } \\
\text { for rural and remote Australian students }\end{array}$ & $\begin{array}{l}\text { External study offering f } \\
\text { earner-learners worldwid }\end{array}$ \\
\hline Mainly print based distance delivery & Increasingly online flexil \\
\hline Relatively low student/staff ratios & Relatively high student/s \\
\hline $\begin{array}{l}\text { Communication and information technology } \\
\text { for experts }\end{array}$ & $\begin{array}{l}\text { Communication and info } \\
\text { technology essential and }\end{array}$ \\
\hline $\begin{array}{l}\text { Collegial, discipline based decision making } \\
\text { processes }\end{array}$ & The university as corpor: \\
\hline 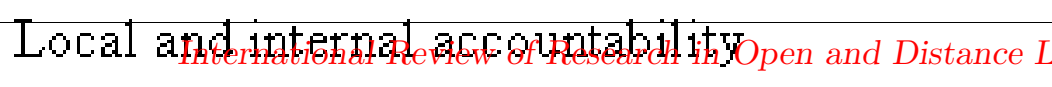 & Finthlic accountability an \\
\hline Main source of funding government & $\begin{array}{l}\text { Main source of funding } 1 \\
\text { government }\end{array}$ \\
\hline
\end{tabular}


Table 2

\begin{tabular}{|c|c|}
\hline Policy area and date & Summary of scope and effect \\
\hline $\begin{array}{l}\text { Commercialisation, intellectual } \\
\text { property, rewarding commercial } \\
\text { activity: University Activities } \\
\text { Policy (2001) }\end{array}$ & $\begin{array}{l}\text { The scope of this policy covers staff activities inv } \\
\text { generation. It deals with requirements of competi } \\
\text { required by the Australian Trade Practices Act, qu } \\
\text { associated with contractual work and consultancie } \\
\text { accounting and the disbursement of profit. The po } \\
\text { teaching and curriculum development for award a } \\
\text { programs and courses regardless of location or mo } \\
\text { The effect of the policy brings together the issues } \\
\text { associated with development and ownership of res } \\
\text { courses, manage ment and teaching costs and plac } \\
\text { quality assurance and accounting procedures. }\end{array}$ \\
\hline $\begin{array}{l}\text { Copyright: Policy and guidelines } \\
\text { relating to copyright and licensing } \\
\text { arrangements arising from Digital } \\
\text { Amendment Act, } 2001\end{array}$ & $\begin{array}{l}\text { The Digital A mendment Act and likely changes it } \\
\text { and costs of licensing arrangements for copying } \\
\text { copyright materials may impact significantly on c } \\
\text { universities. This is providing the impetus for stro } \\
\text { of institutional policy and guidelines on using cop } \\
\text { resource based teaching and learning. }\end{array}$ \\
\hline $\begin{array}{l}\text { Regulation of } \\
\text { contractual } \\
\text { relationships when } \\
\text { operating with } \\
\text { educational } \\
\text { brokers/agents/ } \\
\text { external parties (200l } \\
\text { and I9g9 -- within } \\
\text { program approval } \\
\text { processes) }\end{array}$ & $\begin{array}{l}\text { This area has become a major part of the program } \\
\text { where Academic Policy Review Committee consi } \\
\text { their delivery arrangements. Key areas of concerr } \\
\text { induction and quality assurance of teachers who a } \\
\text { extemal agents, quality control/moderation of faci } \\
\text { examinations, contractual arrangements regarding } \\
\text { and use of course materials. }\end{array}$ \\
\hline $\begin{array}{l}\text { Quality assurance and } \\
\text { improvement of } \\
\text { programs, courses and }\end{array}$ & $\begin{array}{l}\text { Generation of new programs and specialist offsho } \\
\text { income generation means that resources are used } \\
\text { of existing and development of new programs. Th }\end{array}$ \\
\hline $\begin{array}{l}\text { teaching (crurentily } \\
\text { under review) }\end{array}$ & $\begin{array}{l}\text { if equpres strategicallwitmeans paying attention to } \\
\text { viability of programs and resources used for alterr } \\
\text { mechanis ms. The policy will include a program v } \\
\text { derived from a number of indicators. Academic a } \\
\text { viability reports for programs that are identified by } \\
\text { likely that the use of this measure will bring into } \\
\text { competing interests arising from commercial cons }\end{array}$ \\
\hline
\end{tabular}


Figure 1

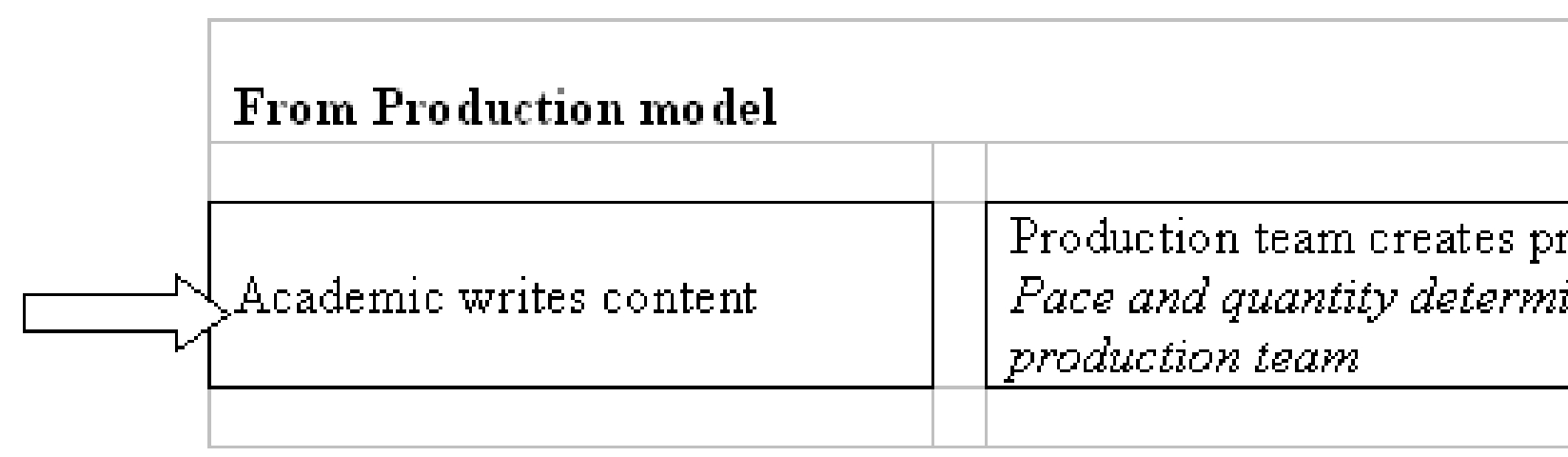

\section{To Enabling (professional development) model}

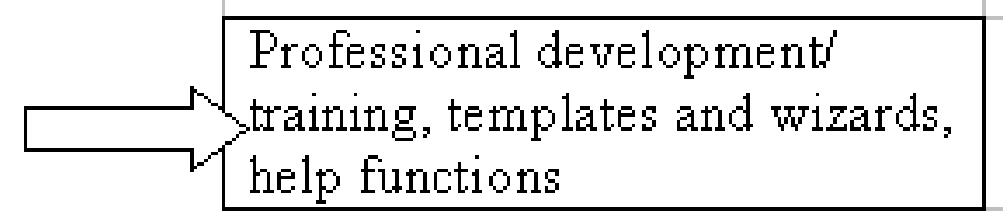

Academic creates product Pace and quantity determ teachers and desktop capa 
Table 3

\begin{tabular}{|l|l|l|}
\hline \multicolumn{1}{|c|}{$\begin{array}{c}\text { Face-to-face education } \\
\text { (Te acher centred) }\end{array}$} & $\begin{array}{c}\text { Distance education } \\
\text { (Resource centred) }\end{array}$ & $\begin{array}{r}\text { Online educ: } \\
\text { (Learner cen }\end{array}$ \\
\hline $\begin{array}{l}\text { Instruction based on teacher } \\
\text { performances }\end{array}$ & $\begin{array}{l}\text { Instruction contained in } \\
\text { materials }\end{array}$ & $\begin{array}{l}\text { Instruction based on acce } \\
\text { interactions - all can be c }\end{array}$ \\
\hline $\begin{array}{l}\text { Located in time, place and } \\
\text { with fixed groups of people }\end{array}$ & $\begin{array}{l}\text { Time and place more } \\
\text { flexible }\end{array}$ & $\begin{array}{l}\text { Flexible personal access, } \\
\text { time or space }\end{array}$ \\
\hline People are scheduled & Materials are scheduled & $\begin{array}{l}\text { Asynchronous opportunit } \\
\text { determines }\end{array}$ \\
\hline Ephemeral experience & Lasting resources & Ephe meral or lasting \\
\hline $\begin{array}{l}\text { High marginal cost limits } \\
\text { scalability }\end{array}$ & $\begin{array}{l}\text { High fixed cost requires } \\
\text { large scale operation }\end{array}$ & Variable fixed and margir \\
\hline Materials support teacher & Materials support learner & $\begin{array}{l}\text { WWW-based resources p } \\
\text { time by (and for) teachers }\end{array}$ \\
\hline
\end{tabular}

